\title{
Experimental Research on water driving oil of Natural Core Series Displacement Method
}

\author{
C Wang1, Z Sun'*, Y Sun², Q Sun' \\ 1. School of Petroleum Engineering, Northeast Petroleum \\ University, Daqing, China \\ 2. The Fourth Oil Production Plant of Daqing Oilfield Co., \\ Ltd., Daqing, China
}

\begin{abstract}
Jilin Oilfield in the Songliao Basin has gone through three stages of increase, stabilization and decrease in crude oil production during the development process. In this paper, the water flooding experiment was carried out by means of rock core in series combination, to analyze and study the water flooding characteristic curve and the recovery ratio curve of the core in Jilin Oilfield. According to the experimental analysis, when the PV number changed slightly (usually $0 \sim 1$ ), the pressure at the monitoring point and the instantaneous liquid volume increased, and the water flood front, the oil displacement efficiency and the water cut increased significantly. When the injected PV number continued to increase (PV number $>1$ ), the pressure at the monitoring point changed slowly, the water flood front, the oil output and the water cut increased slightly, and the oil displacement efficiency was low. According to the experimental results, we explored the characteristics of water flooding by means of rock core in series combination to improve the recovery ratio of the oilfield.
\end{abstract}

\section{INTRODUCTION}

The rock core in series combination will affect the recovery efficiency of the rock core, and the recovery efficiency of a single core varies from the core injection end to the production end [1]. Jilin Oilfield has been developed for 50 years [2], and most of the blocks are currently in the late stage of development, with low recovery. Therefore, it is of great significance for improving oil recovery to study the water flooding characteristics of the core at all times in the long core series combination displacement. In order to improve the core recovery, many scholars at home and abroad have carried out a lot of research on water flooding: Deng Ruijian [3] made a core series combination model using natural cores, conducted an experimental study on the influence of plane heterogeneity on the water flooding effect, and put forward the equivalent mean permeability of radial flow and other concepts. In addition, he made an experimental simulation based on the change of core length, the different combination sequences and other conditions, and then summarized the factors affecting the efficiency of the reservoir. Zhang Jiang et al. [4] selected natural cores from the oilfield, made the 
laboratory multi-core series simulation experiment device and performed the actual simulation operation, in order to provide the laboratory with actual oilfield development means and improve water flooding efficiency. Lu Yan et al. [5] carried out an experimental study on the rock resistivity and relative permeability in water flooding, and discussed the change law of reservoir parameters theoretically. The research results provide a theoretical basis for the optimization of the water flooding formation water saturation model and the correct selection of parameters. To study the effective enhanced oil recovery methods, Wentong Zhang [6] conducted the laboratory experiment to explore the effect of DC voltage, brine concentration and water injection mode on oil displacement efficiency. Li Zhongfeng et al. [7] established a three-dimensional physical model and conducted a laboratory water flooding physical simulation experiment using the constant-rate water injection method. Lu Ruibin et al. [8] carried out water flooding high-power displacement experimental research, formed a highpower displacement oil displacement efficiency calculation method. Zhou Yibo et al. [9] pointed out that active water flooding can effectively produce part of the crude oil in the micronano pores, and the lower core permeability, the better active water flooding for crude oil. Xing Yu,Huang et al. [10] conducted laboratory experiments to study the characteristics of water drive gas, gas drive water, and gas-water two-phase seepage characteristics of multilayer long cores.

Scholars have conducted a large number of experimental studies on water flooding, but have not systematically studied the characteristic parameters such as the pressure at the monitoring point, the instantaneous liquid volume and the resistivity during the displacement process [11-13]. In order to better study the scientific research and production of the oilfield, we made a long core series simulation experiment device, and carried out the simulation operation. The simulation of the water flooding experiment by means of rock core in series combination aims to analyze the fluid production, the oil production, the pressure at each monitoring point, the resistivity and other data of the core at all times during water flooding, so as to calculate its water cut and recovery factor, and thus provide theoretical basis for improving oil recovery of the oilfield.

\section{EXPERIMENTAL MATERIALS}

The experimental water was the formation water sample prepared according to the standard (salinity: $30 \mathrm{~g} / \mathrm{L}$ ). Before the experiment, the impurities in the water were removed to prevent core blockage. The experimental oil was degassed crude oil taken from the Jilin Oilfield, and the experimental environment temperature was $45^{\circ} \mathrm{C}$. The experimental cores were pouring natural cores (in series combination) from well sections Ji+218-203\#-81291.65-1291.95/63, $\mathrm{Ji}+218-203 \#-61266.70-1267.05 / 44$, Ji +218-203\#-171376.50-1376.90/145. The experiment was divided into seven groups, with a total of 28 standard core plugs, and the physical parameters of selected cores are shown in Table 1. 
Table 1. Basic parameters of core

\begin{tabular}{ccccccc}
\hline \multirow{2}{*}{$\begin{array}{c}\text { Number } \\
\text { of groups }\end{array}$} & Serial core number & $\begin{array}{c}\text { Permeability saturated saturated porosity } \\
\text { mD } \\
\text { water ml }\end{array}$ & oil ml & $\begin{array}{c}\text { oil } \\
\text { saturation } \\
\text { \% }\end{array}$ \\
\hline 1 & & & & & & 63 \\
2 & $\mathrm{Ji}+218-203 \#-8-C-20$ & 1.24 & 14.2 & 9.0 & 14.47 & 68 \\
3 & $\mathrm{Ji}+218-203 \#-6-C-30$ & 0.45 & 23.7 & 16.1 & 16.10 & 64 \\
4 & $\mathrm{Ji}+218-203 \#-8-C-30$ & 0.57 & 20.6 & 13.1 & 14.00 & 64 \\
5 & $\mathrm{Ji}+218-203 \#-8-C-40$ & 1.21 & 27.8 & 17.8 & 14.17 & 64 \\
6 & $\mathrm{Ji}+218-203 \#-17-C-50$ & 0.46 & 34.8 & 22.6 & 14.19 & 65 \\
7 & $\mathrm{Ji}+218-203 \#-6-C-50$ & 0.58 & 36.1 & 24.0 & 14.72 & 66 \\
\hline
\end{tabular}

\section{CORE MAKING}

\subsection{Drilling of Standard Core Plugs}

The standard cores with a diameter of $25 \mathrm{~mm}$ were bonded and connected as the long cores needed in the experiment. First, the full-diameter core samples were drilled as $2.5 \mathrm{~cm}$ standard core plugs. The experimental apparatus and drilling results are shown in Figure 1.

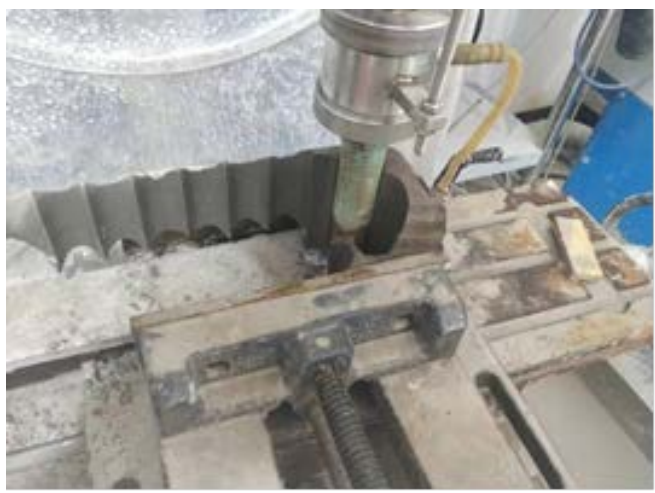

(a)



(b)

Figure 1. experimental apparatus and drilling results 


\subsection{Core Arrangement}

Standard core plugs with a diameter of $2.5 \mathrm{~cm}$ were selected for the displacement experiment. In previous experiments, artificial cores were used for simulation, and the experimental results obtained by artificial cores are different from those obtained by natural cores. The cores used in this experiment, taken from natural cores in Jilin Oilfield, were representative samples. The core plug data table is shown in Appendix 1.

Appendix 1. core column data table

\begin{tabular}{|c|c|c|c|c|c|c|c|c|}
\hline \multicolumn{3}{|c|}{$\begin{array}{c}\mathrm{Ji}+218-203 \#-17 \\
1376.50-1376.90 / 145\end{array}$} & \multicolumn{3}{|c|}{$\begin{array}{c}\mathrm{Ji}+218-203 \#-6 \\
1266.70-1267.05 / 44\end{array}$} & \multicolumn{3}{|c|}{$\begin{array}{c}\mathbf{J i}+218-203 \#-8 \\
1291.65-1291.95 / 63\end{array}$} \\
\hline $\begin{array}{c}\text { Core } \\
\text { number }\end{array}$ & $\begin{array}{r}\text { Core } \\
\text { size, } \mathrm{mm}\end{array}$ & $\begin{array}{c}\text { permeability } \\
\text { mD }\end{array}$ & $\begin{array}{c}\text { Core } \\
\text { number }\end{array}$ & $\begin{array}{c}\text { Core } \\
\text { size, } \mathrm{mm}\end{array}$ & $\begin{array}{c}\text { permeability } \\
\text { mD }\end{array}$ & $\begin{array}{c}\text { Core } \\
\text { number }\end{array}$ & $\begin{array}{c}\text { Core } \\
\text { size, } \mathrm{mm}\end{array}$ & $\begin{array}{c}\text { permeability } \\
\mathrm{mD}\end{array}$ \\
\hline $1-1$ & 40.1 & 0.59 & $2-1$ & 46.7 & 1.23 & 3-1 & 46.9 & 1.36 \\
\hline $1-2$ & 47.1 & 0.59 & $2-2$ & 43.2 & 1.3 & $3-2$ & 26 & 0.41 \\
\hline $1-3$ & 48.8 & 0.58 & $2-3$ & 33.7 & 1.26 & $3-3$ & 46.6 & 1.48 \\
\hline $1-4$ & 50.1 & 0.56 & $2-4$ & 49.8 & 1.2 & $3-4$ & 47.7 & 1.51 \\
\hline $1-5$ & 50 & 0.62 & $2-5$ & 45.8 & 0.41 & $3-5$ & 50.6 & 0.47 \\
\hline $1-6$ & 50 & 0.54 & $2-6$ & 45 & 0.49 & $3-6$ & 47 & 0.44 \\
\hline $1-7$ & 49.9 & 0.59 & $2-7$ & 49.6 & 1.21 & $3-7$ & 46.3 & 0.49 \\
\hline $1-8$ & 50.8 & 0.38 & $2-8$ & 43.6 & 1.02 & $3-8$ & 46.1 & 1.16 \\
\hline $1-9$ & 50.4 & 0.52 & $2-9$ & 38.8 & 1.42 & $3-9$ & 38.6 & 0.5 \\
\hline $1-10$ & 45.6 & 0.53 & $2-10$ & 36.6 & 1.29 & $3-10$ & 34.2 & 1.11 \\
\hline $1-11$ & 48 & 0.66 & $2-11$ & 25.4 & 1.3 & $3-11$ & 35.1 & 0.64 \\
\hline $1-12$ & 39.8 & 0.46 & $2-12$ & 49.5 & 1.31 & $3-12$ & 39.5 & 0.53 \\
\hline $1-13$ & 35.1 & 1.08 & $2-13$ & 52 & 0.48 & $3-13$ & 50.8 & 0.47 \\
\hline $1-14$ & 31.1 & 0.62 & $2-14$ & 47.9 & 0.40 & $3-14$ & 49.5 & 0.44 \\
\hline $1-15$ & 55.4 & 0.58 & $2-15$ & 33.1 & 0.72 & 3-15 & 50.8 & 0.39 \\
\hline $1-16$ & 51.4 & 0.59 & $2-16$ & 44.7 & 1.33 & $3-16$ & 52 & 1.27 \\
\hline $1-17$ & 56.7 & 1.34 & $2-17$ & 57 & 1.19 & $3-17$ & 55 & 1.24 \\
\hline $1-18$ & 61.1 & 1.26 & $2-18$ & 46.1 & 1.39 & 3-18 & 92 & 0.52 \\
\hline $1-19$ & 61.3 & 1.44 & $2-19$ & 85 & 0.50 & 3-19 & 91.6 & 1.13 \\
\hline $1-20$ & 58.3 & 0.51 & $2-20$ & 90 & 0.49 & $3-20$ & 91.9 & 0.51 \\
\hline $1-21$ & 58.1 & 1.28 & $2-21$ & 88.8 & 1.17 & $3-21$ & 91.1 & 0.57 \\
\hline $1-22$ & 62.9 & 0.35 & $2-22$ & 92.3 & 1.18 & $3-22$ & 91.4 & 0.49 \\
\hline $1-23$ & 61.8 & 0.59 & $2-23$ & 90.1 & 0.45 & $3-23$ & 92.1 & 0.47 \\
\hline $1-24$ & 90.1 & 1.37 & $2-24$ & 87.7 & 1.31 & $3-24$ & 91.5 & 0.61 \\
\hline $1-25$ & 87.4 & 0.54 & $2-25$ & 91.8 & 0.47 & $3-25$ & 87.4 & 1.23 \\
\hline $1-26$ & 91.1 & 1.18 & $2-26$ & 86 & 1.19 & $3-26$ & 92.5 & 1.21 \\
\hline $1-27$ & 93.2 & 0.53 & $2-27$ & 51 & 1.40 & $3-27$ & 49.3 & 0.57 \\
\hline $1-28$ & 91.4 & 1.35 & $2-28$ & 55.3 & 1.19 & $3-28$ & 44.2 & 0.69 \\
\hline $1-29$ & 90.6 & 0.66 & $2-29$ & 76.3 & 0.49 & $3-29$ & 23.9 & 0.45 \\
\hline $1-30$ & 91.8 & 0.39 & $2-30$ & 79.6 & 0.51 & & & \\
\hline $1-31$ & 92.1 & 0.41 & $2-31$ & 80.1 & 1.27 & & & \\
\hline $1-32$ & 92.5 & 0.62 & $2-32$ & 59.3 & 1.3 & & & \\
\hline $1-33$ & 90.4 & 0.63 & & & & & & \\
\hline $1-34$ & 90.2 & 1.31 & & & & & & \\
\hline $1-35$ & 92.3 & 0.58 & & & & & & \\
\hline
\end{tabular}


20-60 cm long cores used in this experiment cannot be made with the existing coring technology. Therefore, short cores with a diameter of $2.5 \mathrm{~cm}$ were connected as $20,30,40$, $50,60 \mathrm{~cm}$ long cores in the experiment. The expression of the core arrangement is shown in (1) [14]:

$$
\frac{L}{\bar{K}}=\frac{L_{1}}{K_{1}}+\frac{L_{2}}{L_{3}}+\cdots \frac{L_{i}}{K_{i}}+\cdots \frac{L_{n}}{K_{n}}=\sum_{i=1}^{n} \frac{L_{i}}{K_{i}}
$$

where, $\bar{K}$ is the core harmonic mean permeability, $10-3 \mathrm{~m}^{2}$, and $L$ means the total length of the core, $\mathrm{cm}$.

When the cores were connected in series for the water flooding experiment, the liquid flow through the cross section of each core was the same, the pressure difference at the two ends of the core was different, and the pressure distribution followed the law of equivalent seepage resistance. Therefore, the harmonic mean permeability of the core series combination should be the equivalent mean permeability of the rock core in series combination [15].

Firstly, the value of $\bar{K}$ was obtained by the formula (1) and then compared with the core used in the experiment. The cores with the permeability closest to the value of $\bar{K}$ were put in the first place. For other cores, the value of $\bar{K}$ was calculated by the formula (1), and those with the permeability closest to the value of $\bar{K}$ were put in the second place. The cores were arranged in this order and divided into 7 groups. The arrangement of cores in the experiment is shown in Table 2.

Table 2. Basic core column allocation table for series experiment

\begin{tabular}{lllllllll}
\hline Serial core number & \multicolumn{1}{l}{ Distribution core column } \\
\hline C-28-1 2 & $3-1$ & $3-8$ & $3-16$ & $3-17$ & & & & \\
C-28-3 5 & $2-5$ & $2-6$ & $2-14$ & $2-19$ & $2-29$ & & & \\
C-28-6 8 & $3-9$ & $3-11$ & $3-22$ & $3-24$ & $3-28$ & & & \\
C-28-9 12 & $3-3$ & $3-4$ & $3-10$ & $3-19$ & $3-25$ & $3-26$ & & \\
C-28-13 17 & $1-10$ & $1-11$ & $1-12$ & $1-30$ & $1-31$ & $1-33$ & $1-35$ & \\
C-28-18 22 & $2-1$ & $2-4$ & $2-13$ & $2-20$ & $2-23$ & $2-25$ & $2-30$ & \\
C-28-23 28 & $1-17$ & $1-18$ & $1-19$ & $1-21$ & $1-24$ & $1-26$ & $1-28$ & $1-34$ \\
\hline
\end{tabular}

\subsection{Drilling of Electrode Holes and Pressure Test Holes}

Electrodes were required for cores used in this experiment. By considering the extremely low permeability of the core and summarizing previous experiences of the electrode core water flood front test, the electrode spacing was set as $2.5 \mathrm{~cm}$, and the electrode hole depth was set as about $2 \mathrm{~cm}$. In order to test the water flooding response time more accurately, the pressure test points were arranged according to the number of two pressure test points in $20 \mathrm{~cm}$, three pressure test points in $30 \mathrm{~cm}$, four pressure test points in $40 \mathrm{~cm}$, and so on. The electrode hole was about $2 \mathrm{~cm}$ deep, and the pressure test hole was about $1.25 \mathrm{~cm}$ deep. 


\subsection{Electrode Placement}

Hydrogen annealed wire electrodes with a length of $10 \mathrm{~cm}$ and a diameter of $0.11 \mathrm{~cm}$ were used in this experiment. First, the colloidal quartz sand with the same permeability as the core was prepared. The quartz sand was filled into the drilled electrode hole, and properly rammed and flattened using a small iron rod with the same diameter as the electrode hole, to ensure that the electrode can be inserted. Then, the electrode was inserted along one side of the electrode hole, and the spacing between each electrode pair should be $2.5 \mathrm{~cm}$. The electrode hole was rammed and flattened again with a thinner iron rod and sealed with epoxy resin colloidal particles to ensure the stability of the electrode. The schematic diagram of electrode placement is shown in Figure 2.

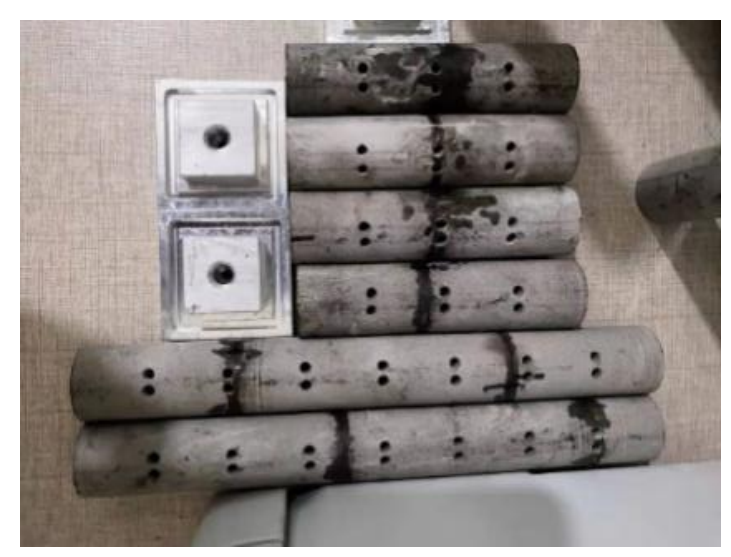

(a)

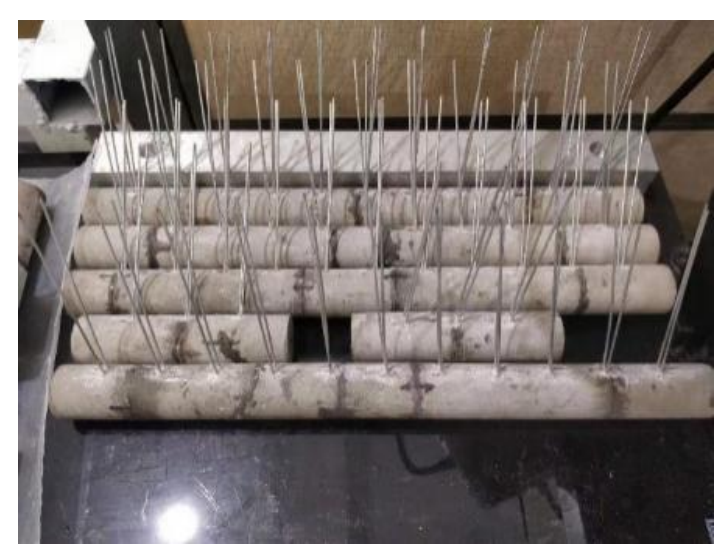

(b)

Figure 2. Schematic diagram of electrode placement 
3.5. Core End Cover, Arrangement of Pressure Test Points and Core Gluing In the experiment, the end covers of the core and the pressure test point were made of aluminum alloy, and bonded to the core end face and the pressure test hole, respectively. In addition, a thin layer of epoxy resin glue should be applied to the surface of the core plug to prevent excessive infiltration of the epoxy resin glue into the core when directly poured. The arrangement of core end covers and pressure test points is shown in Figure 3, and the core pregluing treatment is shown in Figure 4.

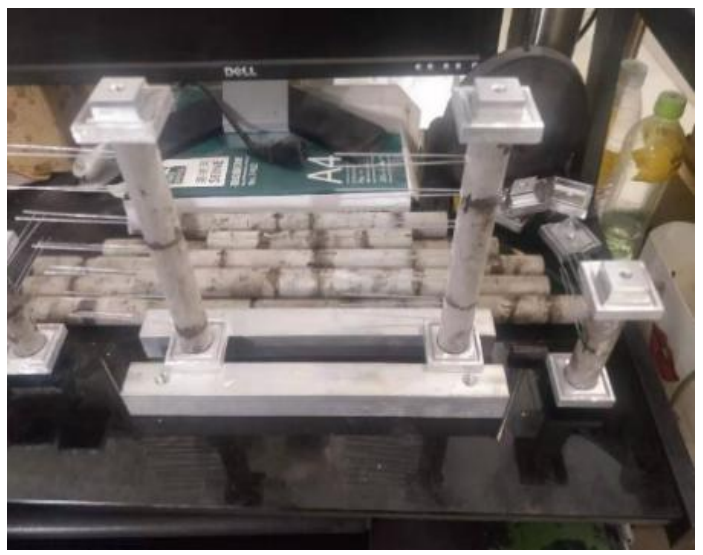

(a)

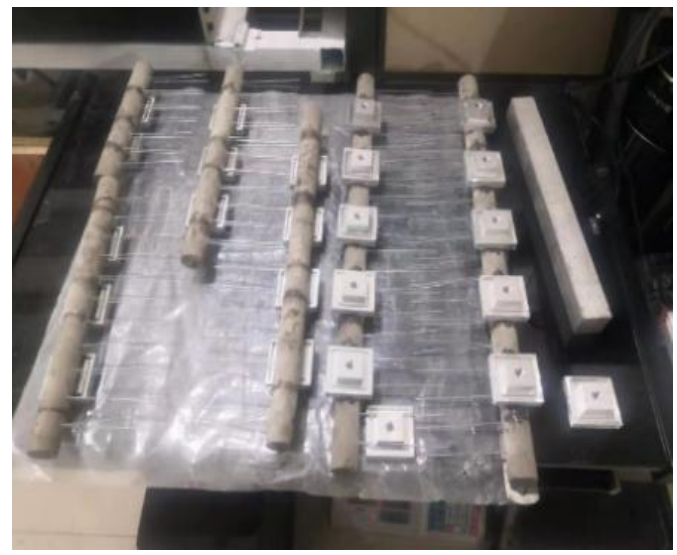

(b)

Figure 3. end cap bonding diagram 


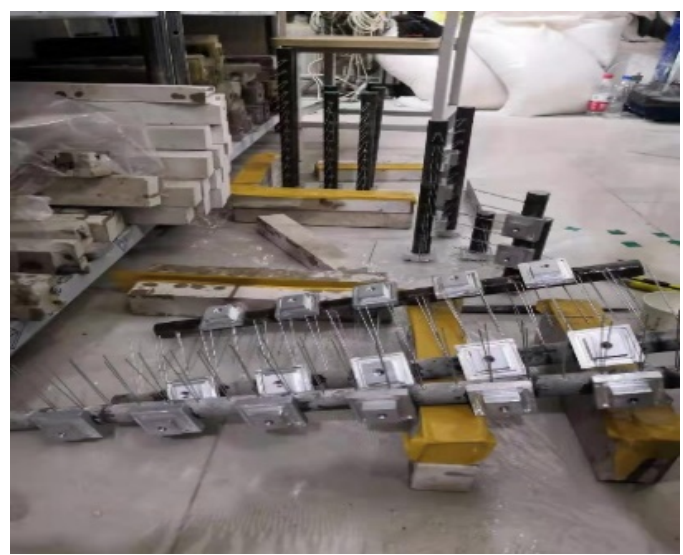

Figure 4. Core pre-brushing treatment

\subsection{Electrode Bending Treatment and Core Pouring}

In this experiment, all electrodes should be bent, and the electrodes of the rock core in series combination should be in the same direction as the end cover of the pressure test point to facilitate core pouring. The prepared cores were put into the pouring mold, and the two ends were sealed with special plastic plates and plasticine for pouring. The schematic diagram of electrode bending treatment is shown in Figure 5, and the schematic diagram of core pouring is shown in Figure 6.



Figure 5. Schematic diagram of electrode bending treatment 


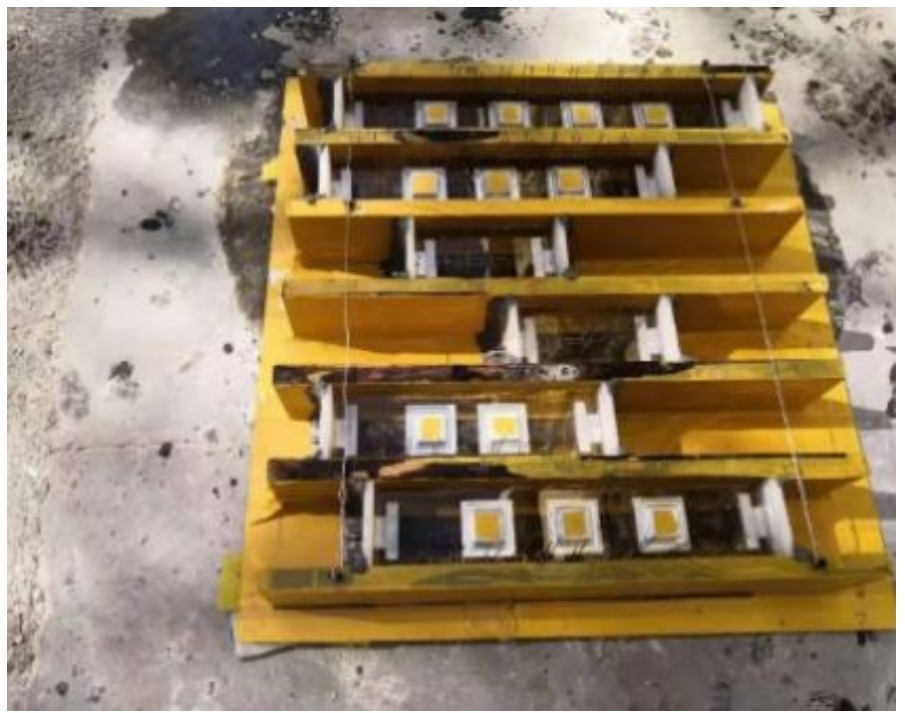

Figure 6. Schematic diagram of core pouring

\section{EXPERIMENTAL PROCESS}

The long core displacement experiment apparatus [16] consists of displacement system (thermostat, constant-flux pump, piston container, pipe valve, etc.), acquisition system (resistivity acquisition device, PT acquisition system), measurement system (pressure measurement, temperature measurement, etc.). The displacement includes saturated core link, core placement link, water flooding link and production link. The experimental process is shown in Figure 7.

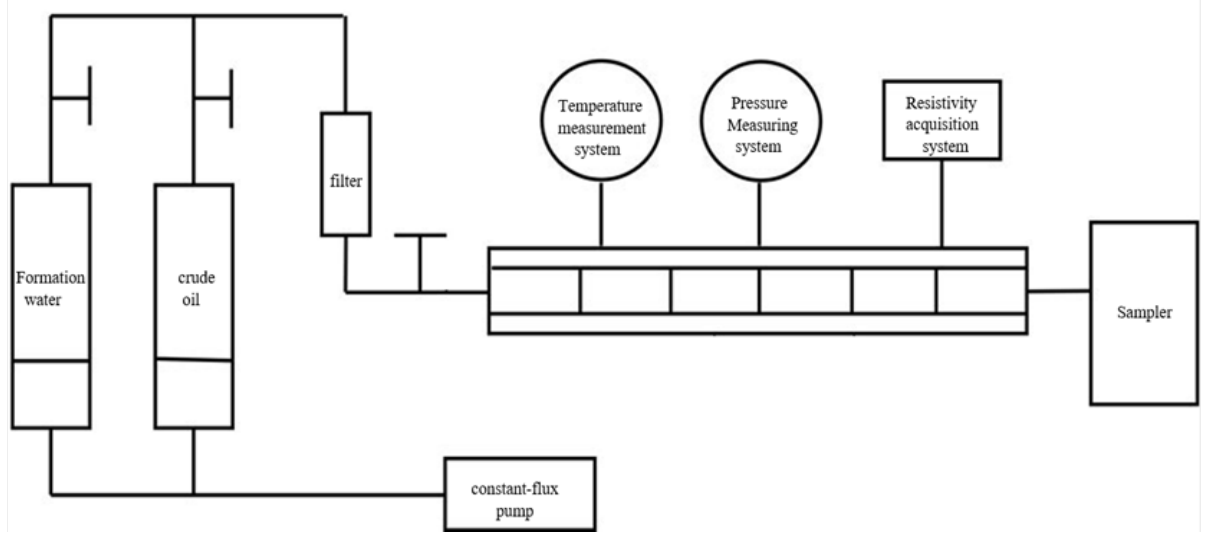

(a) 


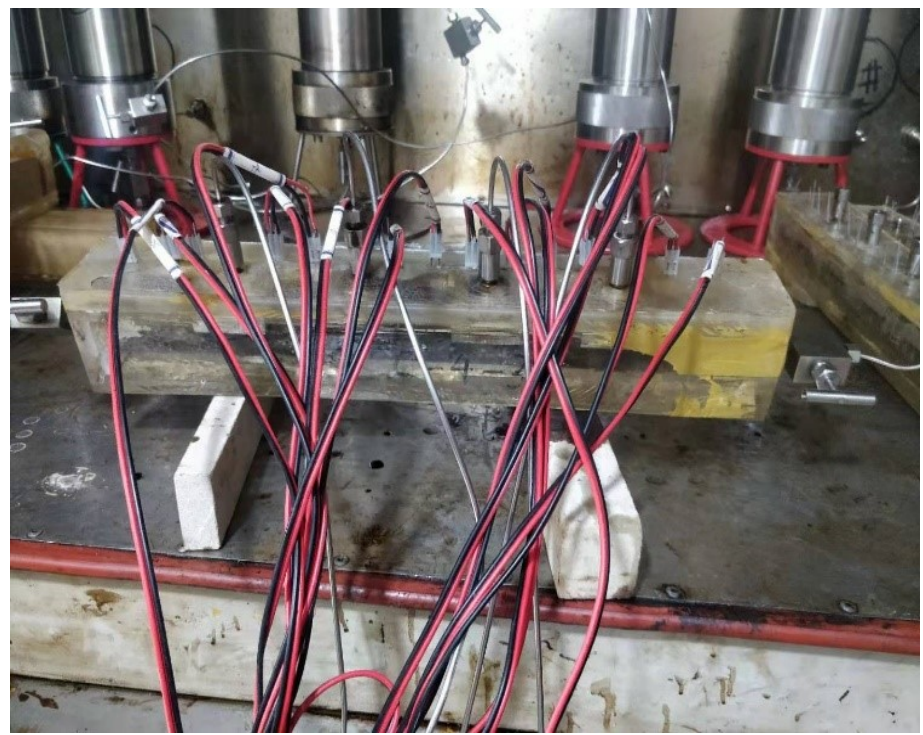

(b)

Figure 7. Experimental flow chart

\section{THE EXPERIMENTAL METHOD}

The experiment was carried out according to GB/T 28912-2012 Test Method for the Relative Permeability of Two-Phase Fluid in Rock. The series displacement experiment was performed using the displacement device and the prepared long natural core [17]. The specific experimental program is shown in Table 3.

Table 3. Long core series displacement test

\begin{tabular}{lccccc}
\hline Tandem core length, cm & 20 & 30 & 40 & 50 & 60 \\
Number of experimental groups & 1 & 2 & 1 & 2 & 1 \\
\hline
\end{tabular}

The experimental method is shown below:

1. The cores were drilled, the aluminum alloy end covers of the core and the pressure test point were bonded to the core end face and the pressure test hole, respectively, and a thin layer of epoxy resin glue was applied to the surface of the core plug;

2. The core saturated oil was grouped for experiment according to the calculated long core series arrangement;

3. The cores were placed in the displacement system, the electrode and the pressure sensor were connected, and the resistivity and pressure test systems were turned on; then the resistivity and pressure changes were recorded;

4. The constant-flux pump was started at $0.02 \mathrm{ml} / \mathrm{min}$ for water flooding at the same rate, and the automatic sampler was started; 
5. The oil-water mixture entered the sampler, and then oil and water were separated and measured separately. The experiment was completed until the comprehensive water cut reached $100 \%$.

6. The resistivity acquisition system, PT acquisition system, oil-water measurement data, etc. were classified and archived for later processing.

\section{EXPERIMENTAL RESULTS}

The experimental results of the first group were analyzed, as shown in Figure 8a was the pressure change law of the core $\mathrm{Ji}+218-203 \#-8-\mathrm{C}-20$; b was the change law of the instantaneous liquid volume and water cut of the core $\mathrm{Ji}+218-203 \#-8-\mathrm{C}-20$; c was the change law of water flood front and recovery degree of the core $\mathrm{Ji}+218-203 \#-8-\mathrm{C}-20$; d was the change law of resistivity of the core $\mathrm{Ji}+218-203 \#-8-\mathrm{C}-20$. According to the analysis:

When the injected PV number increased $(0 \sim 0.5 \mathrm{PV})$, the pressure at the monitoring point, the instantaneous liquid volume, the water flood front, and the recovery ratio increased in varying degrees. This was the initial stage of displacement. Because the pressure and water produced by water flooding cannot reach each core instantly, the water flooding pressure needs to overcome resistance before entering the core near the injection end. This pressure was higher than that at which this core was displaced alone. Therefore, when the injected PV number was $0 \sim 0.5 \mathrm{PV}$, the pressure at the monitoring point, the instantaneous liquid volume and the water flood front reached the maximum value, and the recovery degree increased greatly at this time;

When the PV number was 0.5, water flowed through the front core and reached the middle core. The displacement medium changed from the original oil to the water and oil flowing out of the front core. Because of the hydrophilic nature of the core $[18,19]$, oil was mainly displaced. At the same time, with the advance of the oil-water front, the resistance overcome by the water flood front became smaller [20-22], so the flooding pressure became smaller and the pressure at the monitoring point changed slowly. The crude oil in the core was gradually displaced by the injected water and finally reached the salinity (or resistivity) of the injected water [23]. In this process, the resistivity was changing, that is, when the water cut was 0 , the resistivity was the original resistivity of the core, so the resistivity remained stable and changed slightly. After the formation water was injected, the resistivity decreased greatly; the water cut at the production end was $73.6 \%$, and the recovery ratio was $48.3 \%$.

When the injected PV number was 1:1, the pressure began to remain stable. Both the water flood front and the recovery ratio increased steadily and changed slightly, and the resistivity was close to 0 . At this time, the water cut was $83.7 \%$ and the recovery ratio was $58.3 \%$.

The PV number continued to increase (PV number $>1 \mathrm{PV}$ ). When the water cut was $100 \%$, the experiment ended and the recovery ratio was $61.1 \%$. 


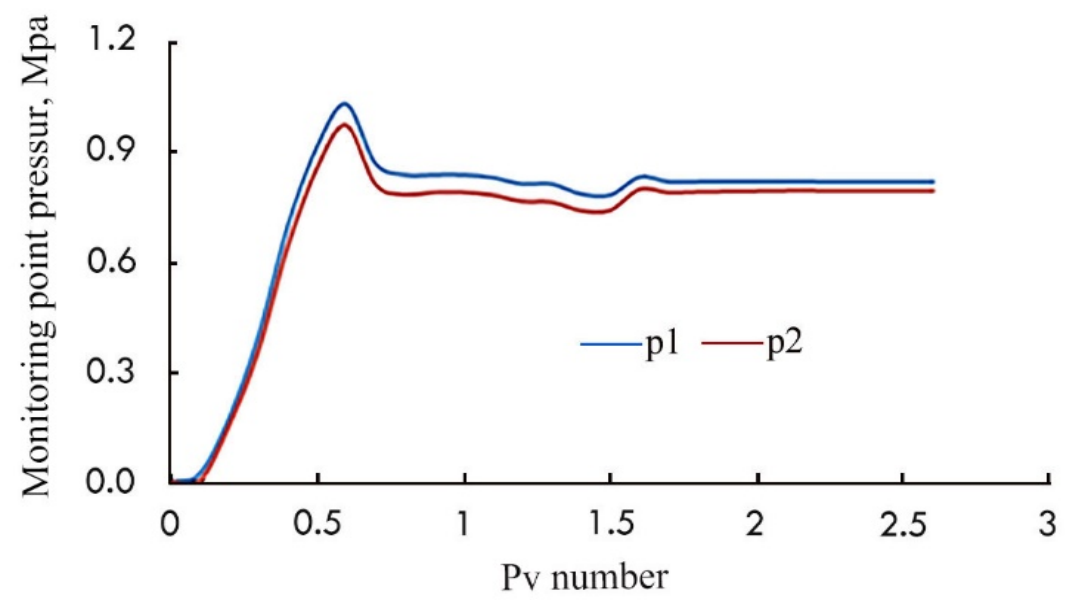

(a) Core Ji+218-203\#-8-C-20 pressure change law

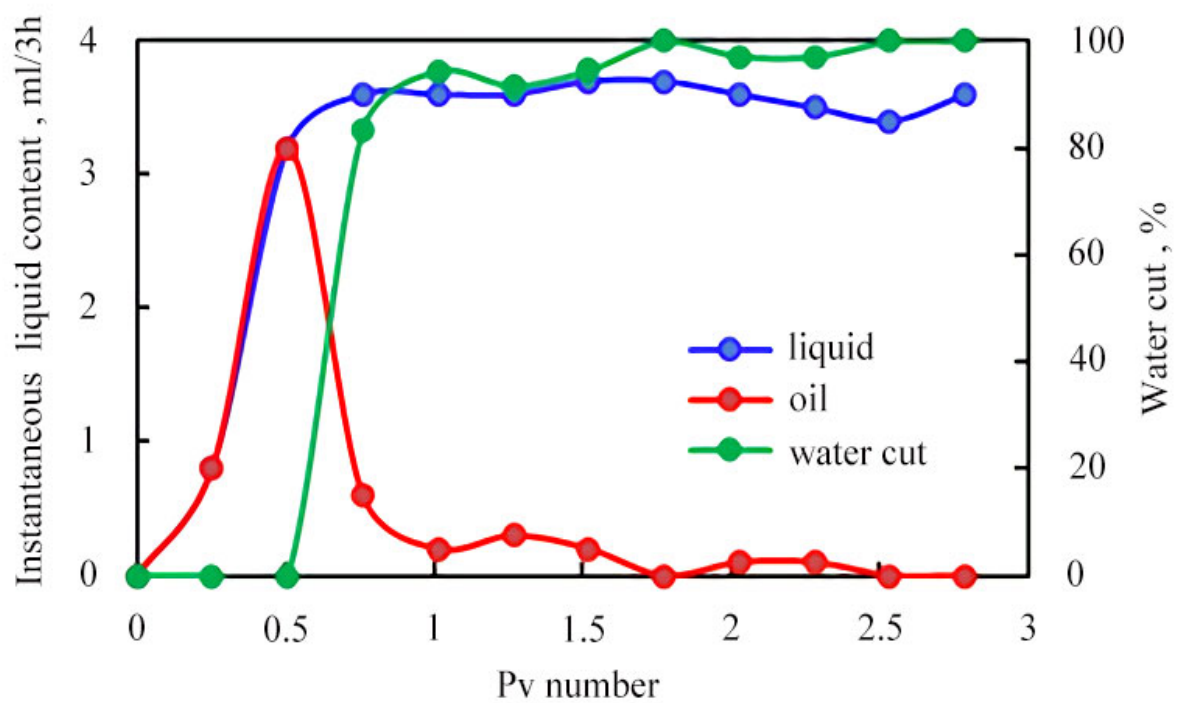

(b) Core Ji+218-203\#-8-C-20 Instantaneous liquid content and water content change law 


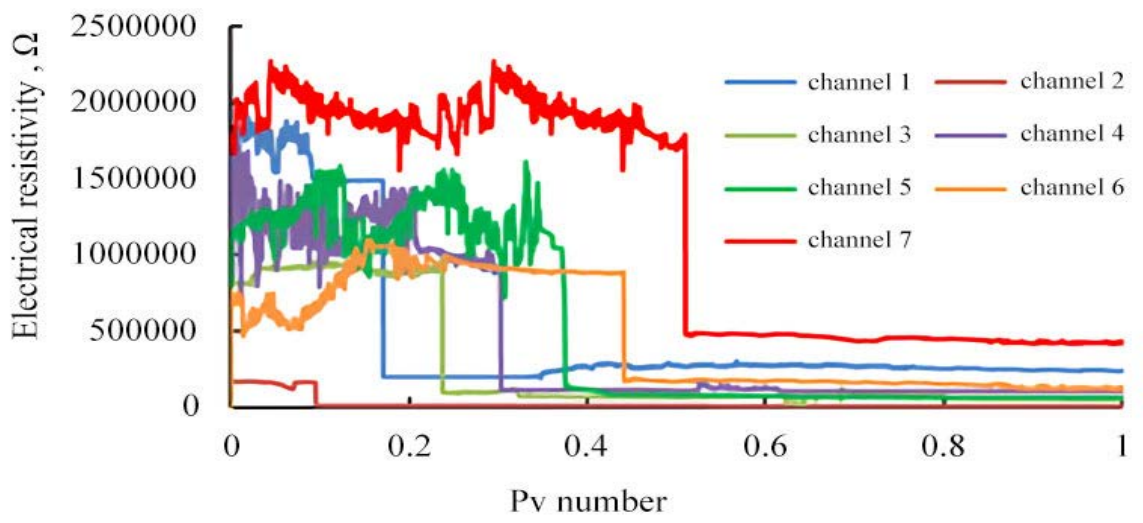

(c) Core Ji+218-203\#-8-C-20 Water flooding Front and Variation Law of Recovery Degree

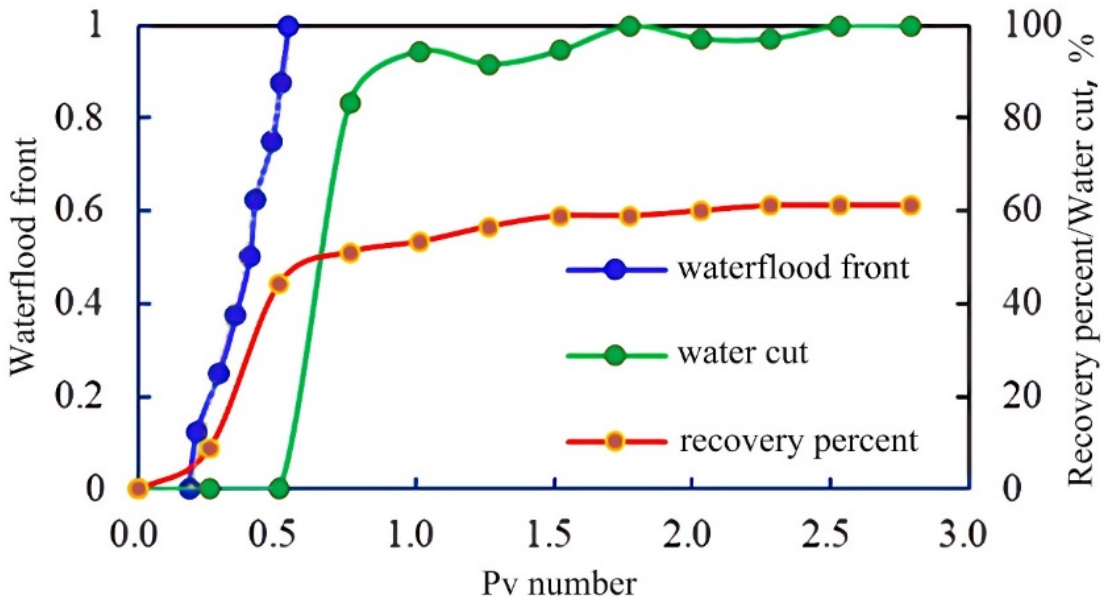

(d) Core Ji+218-203\#-8-C-20 Water flooding Front and Variation Law of Recovery Degree

Figure 8 Core Ji+218-203\#-8-C-20 series displacement experiment results

In order to study the difference of oil recovery by water flooding after the cores of different intervals and different lengths are connected in series, we conducted a total of 7 groups of experiment after the cores were saturated with oil. The experimental results are shown in Table 4. Table 4 shows that the permeability, the development PV, the front PV and the recovery degree were different in each group. 
Table 4. Summary of experimental results

\begin{tabular}{|c|c|c|c|c|c|}
\hline $\begin{array}{l}\text { Number of } \\
\text { groups }\end{array}$ & $\begin{array}{l}\text { Core length } \\
\mathrm{cm}\end{array}$ & $\begin{array}{l}\text { Permeability } \\
\text { mD }\end{array}$ & $\begin{array}{l}\text { mobilization } \\
\text { PV }\end{array}$ & Front PV & $\begin{array}{l}\text { recovery percent } \\
, \%\end{array}$ \\
\hline 1 & 20 & 1.24 & 0.17 & 0.54 & 61.1 \\
\hline 2 & 30 & 0.45 & 0.21 & 0.71 & 57.8 \\
\hline 3 & 30 & 0.57 & 0.20 & 0.61 & 60.3 \\
\hline 4 & 40 & 1.21 & 0.175 & 0.53 & 60.1 \\
\hline 5 & 50 & 0.46 & 0.22 & 0.70 & 55.8 \\
\hline 6 & 50 & 0.58 & 0.21 & 0.60 & 58.3 \\
\hline 7 & 60 & 1.29 & 0.18 & 0.54 & 58.4 \\
\hline
\end{tabular}

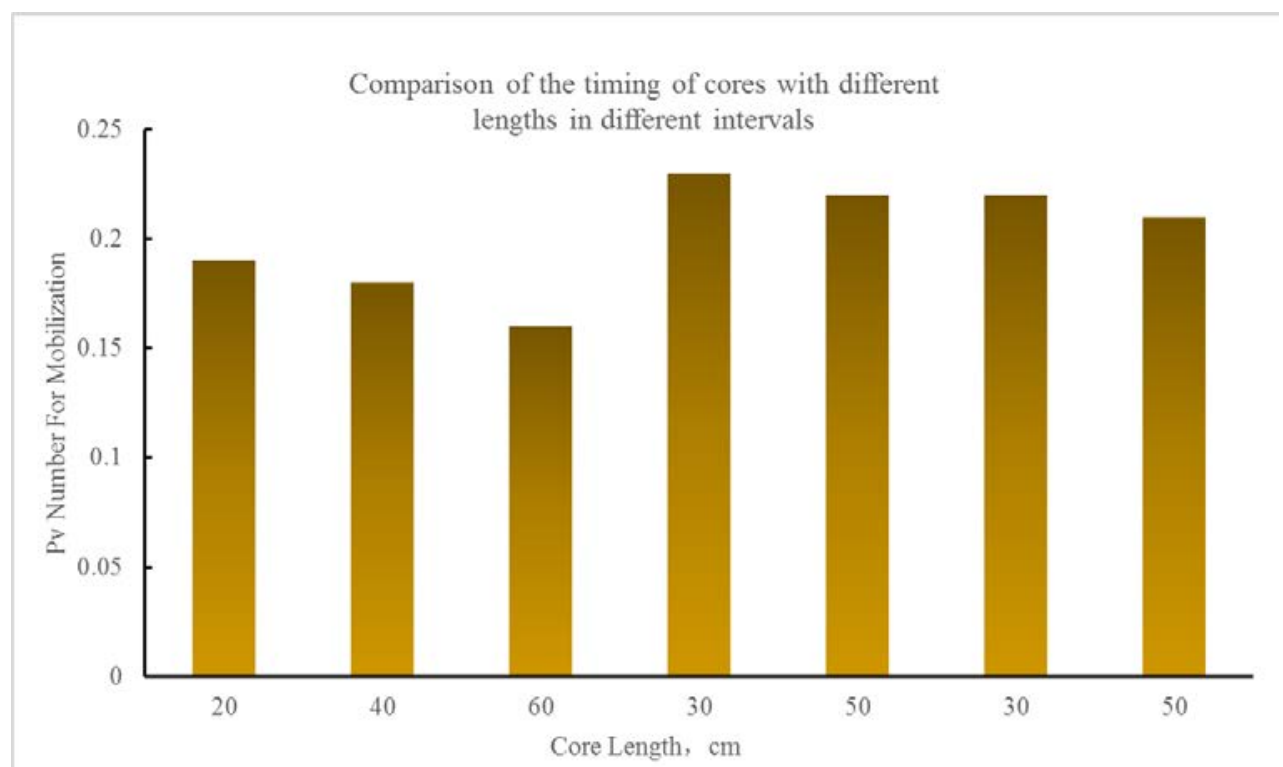

Figure 9. Comparison of core operation opportunities of different lengths in different layers

Figure 9 shows the recovery degree of cores of different intervals and different lengths, and Figure 10 shows the development comparison of cores of different intervals and different lengths. It is observed that when the core interval is the same, the smaller the core length, the greater the recovery degree and the greater the PV number required for development. When the core length is the same, the deeper the interval, the greater the recovery degree and the smaller the PV required for development. 


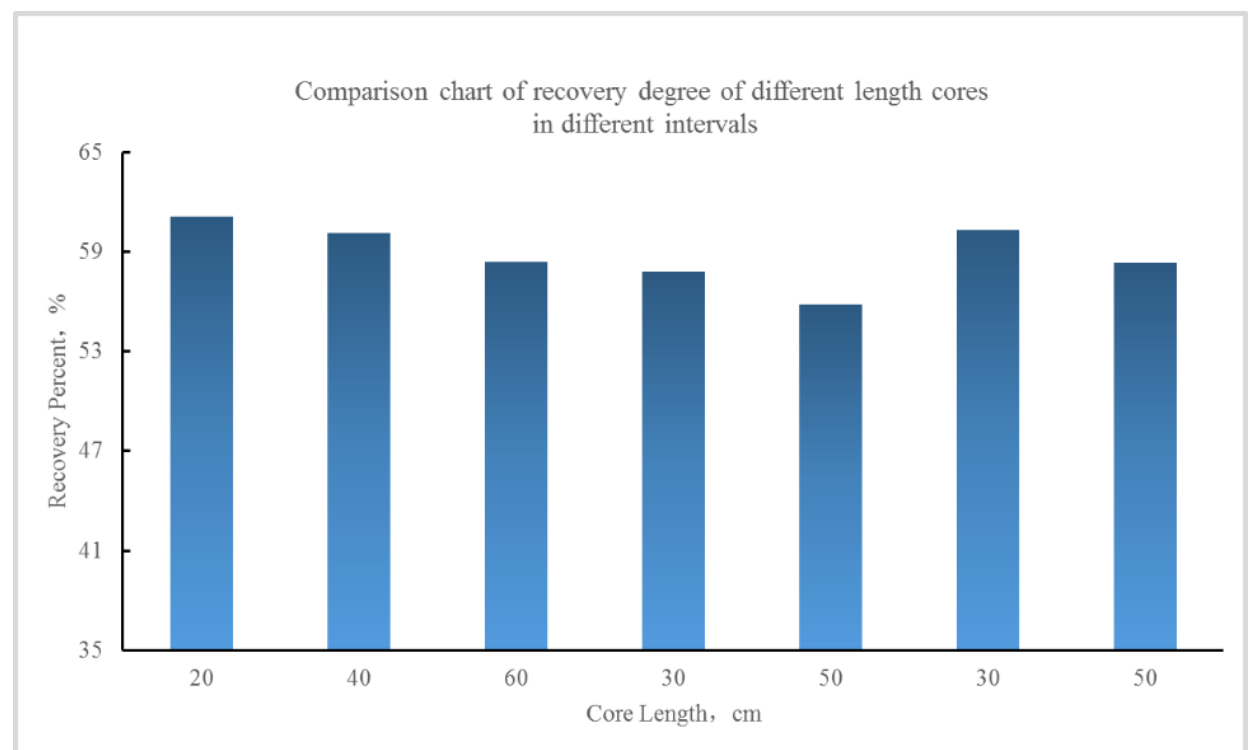

Figure. 10 Comparison diagram of core recovery degree of different length in different layers

\section{CONCLUSION}

By comparing the experimental results of each group and the recovery degree, the displacement results in each group are significantly different:

1. In the long core displacement of the oilfield, the core of the fifth group (50 cm long) had a lower permeability (0.46 md) and it exhibited the lowest production efficiency (55.8\%).

2. Compared with general oilfields, this oilfield had higher crude oil saturation pressure and smaller pressure difference, so the recovery efficiency was relatively low.

3. When cores with similar permeability were subjected to the displacement experiment, as the core length increased, the recovery degree decreased accordingly. In this experiment, when the core length increased by $20 \mathrm{~cm}$, the recovery degree decreased by $1-2 \%$.

4. In the water flooding experiment of cores with similar permeability, as the core length increased, the development PV number decreased slightly (decrease by $0.005-0.1$ )

\section{DATA AVAILABILITY}

The data used to support the findings of this study are included within the manuscript. The data from Figure 1 to Figure 10 are the data used to support the findings of this study.

\section{CONFLICTS OF INTEREST}

No conflict of interest exists in the submission of this manuscript. 


\section{ACKNOWLEDGMENTS}

We thank the editors and the reviewers for their very helpful comments, which led to the better presentation of the ideas proposed in this manuscript.

\section{REFERENCES}

[1] Han Dakuang. Development model of multilayer sandstone reservoirs [M]. Beijing: Petroleum Industry Press, 1999: 91-145

[2] Song Yiwei, Lu Zihong, Ju Dengfeng. Application of Polymer Gel and Microbial Controlled Flooding Technology [J]. Chemical Engineering of Oil and Gas, 2006, 035 (003): 217-221.

[3] Deng ruijian. Experimental study on the influence of reservoir plane heterogeneity on water flooding effect [J]. Daqing petroleum geology and development, 2002 (04) : 16-19 $+83$.

[4] Zhang Jiang, Yang qingyan. development and application of multi-core series simulation experimental device [J]. Journal of petroleum and natural gas (journal of jianghan petroleum institute), 2005 (S1) : 263-264.

[5] Lu yan, Yang qingshan, liu chuanping. Experimental study on physical response characteristics of water flooding rocks [J]. Logging technology, 2008,42 (04) : 371-376.

[6] Wentong Zhang,Zhengfu Ning,Biao Zhang,Qing Wang,Zhilin Cheng,Liang Huang,Rongrong Qi,Xiongtao Shang. Experimental investigation of driving brine water for enhanced oil recovery in tight sandstones by DC voltage[J]. Journal of Petroleum Science and Engineering,2019,180.

[7] Li Zhongfeng, He Shunliu, Men Chengquan, Yang Wenxin. Experimental Study on Remaining Oil of Water Flooding in Heterogeneous 3D Model [J] .Petroleum Drilling \& Production Technology, 2005 (04): 41-44 + 91.

[8] Lu Ruibin, Hu Lin, Liu Shuangqi, Wang Wenjuan, Tang Mingguang. A new method for calculating flooding efficiency of water flooding high-power flooding experiment[J]. Fault Block Oil and Gas Field, 2019, 26(05): 601-604.

[9] Zhou Yibo, Liu Weidong, Sun Linghui, et al. Research on the availability of water flooding in Daqing tight oil reservoirs[J]. Chinese Science and Technology Paper, 2018, 13(21):96-101.

[10]Xing Yu,Huang Quanhua,Wang Chengyin.Experimental research on gas flooding and water flooding with multi-layer long cores in gas reservoirs[J].Chemical Engineering and Equipment,,2020(01):6-8.

[11] Yang Zhengming, Li Zhishuo, Wang Xuewu, et al. A new method for testing relative permeability curves of ultra-low permeability oilfields [J]. Acta Petrolei Sinica, 2010, 31 (4): $629 \sim 632$.

[12] Chen Ping, Tao Guo, Dong Mingzhe, et al. Effect of surface rent roughness on rock-water monkey channel on oil-water two-phase flow [J], Progress in Geophysics, 2013, 28 (2): $824 \sim 829$.

[13] Sun Lijuan,Wu Fan,Liu Sheqin,Zhang Suqin,Rong Guihua,Wang Ruihua.The feasibility experiment of gas injection and oil recovery in ultra-low permeability reservoirs[J].Henan Petroleum,2005(03):38-39+99. 
[14] Gao Jianbo, Liu yuming, zhang qun, et.al. Experimental study on long core displacement in low permeability

[15] reservoirs in weizhou oilfield [J]. Chinese and foreign energy, 2011,16 (03) : 60-63.

[16] He Gengsheng. Reservoir Physics [M]. Beijing: Petroleum Industry Press, 1994: 44-48

[17] He shushan. Research on the drilling fluid system for the protection of oil and gas reservoirs in jilin oilfield [D]. Daqing institute of petroleum, 2002.

[18] Lan Yubo, Xiao Luchuan, Zhao Yuzhen. An improved method for describing the characteristics of two-phase flow in ultra-low permeability reservoirs [J]. Daqing Petroleum Geology and Development, 021 (2): 23-25.

[19] Pedrera B, Bertin H, Hamon G, et al. Wettability Effect on Oil Relative Permeability During a Gravity Drainage[A]. SPE Annual Technical Conference and Exhibition[C].SPE:2002,1-9.

[20] Papatzacos P, Svein MS. Relative Pemeability From Capillary Presure[A]. SPE Annual Technical Conference and Exhibition[C]. SPE:2002,1-11.

[21]Fan Kunkun. Experimental study on water flooding in heterogeneous reservoirs [D]. China University of Petroleum (East China), 2014.

[22] Chen Ting. Microscopic water flooding experiment of heterogeneous reservoir model [J]. Petroleum Geology and Recovery Efficiency, 2007, 14 (4): 72-75.

[23] Xu shouyu ,Li hongnan. The evolution law of reservoir pore-throat network field and remaining oil distribution[J]. Acta Petrolei Sinica,2003(04):48-53.

[24] Zhang min, liu weidong. Study on physical characteristics of rocks in water-flooded strata at different development stages under water flooding [J]. Journal of Yangtze university natural science \& technology, 2009, 6 (1): 48-51. 
118 